\section{The year in numbers}

\section{China}

750 - number of new jobs added to Roche's Chinese workforce this year, representing an increase of $25 \%$.

900 - number of additional reps Pfizer wants to bring to China. 6,000 - number of layoffs worldwide announced by Pfizer in 2010

$\$ 1.6$ billion - price paid by Charles River Laboratories International for one of China's largest drug-research contractors, WuXi AppTec Co.

$\$ 50$ billion - estimated value of the Chinese drug market in 2011, according to market research firm IMS Health.

\title{
Swine flu
}

18,449 - number of confirmed deaths from pandemic H1N1, according to the World Health Organization (WHO).

214 - number of countries affected by the epidemic.

40 million - number of vaccine doses (costing about $\$ 260$ million) incinerated in June 2010 by the US government after they expired.

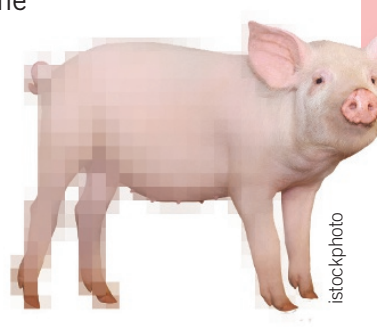

\section{Drugs}

84 - number of new drugs approved by the FDA in 2010 (as of 9 November); it was 95 in 2009.

5 - number of new biologics approved by the FDA in 2010 (as of 9 November); it was 7 in 2009.

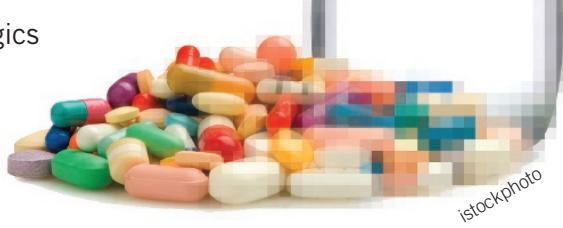

\section{Cancer}

1.3 million - estimated annual deaths from lung cancer worldwide, according to the WHO.

$\$ 2$ billion - profits for Philip Morris International in the second quarter of 2010 alone.

$23 \%-42 \%$ - estimated range of prostate cancers detected by prostate specific antigen (PSA) testing that would otherwise never have been detected in the man's lifetime.

$\$ 93,000$ - the cost of one year of Provenge, the first vaccine to treat prostate cancer, created by Dendreon.

\section{Women in math and science}

13: 1 - proportion of seventh grade boys to girls scoring over 700 on the SAT math section, in 1983 (Science 222, 10291031, 1983).

\section{Stem cells}

76 - number of human embryonic stem cell lines available for NIH funding.

$\$ 1.1$ billion - amount of money allocated by the US National Institutes of Health for stem cell research in its 2011 budget.

\section{Reproduction}

4 million - number of individuals born thanks to in vitro fertilization, as estimated by the Karolinska Institute when they awarded the 2010 Nobel Prize in Medicine to IVF pioneer Robert Edwards.

12 - number of embryos implanted into the womb of Nadya Suleman by her fertility doctor. Suleman subsequently 3.8: 1 - same ratio, 2010 (Intelligence doi: 10.1016/j.intell.2010.04.006, 2010).

$50.7 \%$ - proportion of women earning PhDs in the US in 2008-2009, according to the Council of Graduate Schools. This is the first academic year in which women have overtaken men in earning doctoral degrees.

9 - number of women awarded Nobel Prizes in Medicine to date.

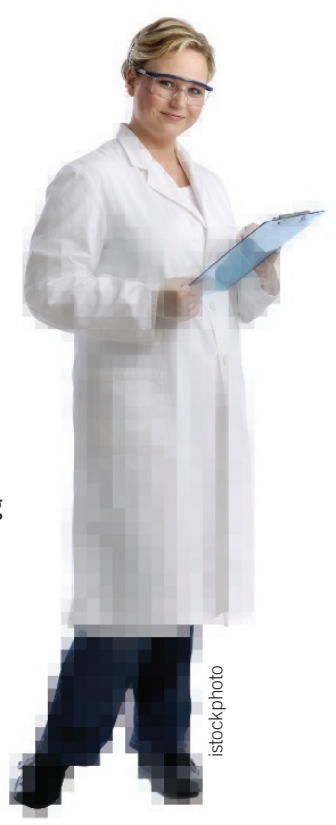

\section{AIDS}

14.6 million - the number of people worldwide supposed to be receiving antiretroviral treatment (ART) for HIVIAIDS, according to new guidelines from the WHO.

9.3 million - the number of people who fall into this category that are not getting ART. 